\title{
Histopathological Evaluation of the Effectiveness of Glycyrrhizic Acid as a Radioprotector Against the Development of Radiation-Induced Lung Fibrosis
}

\author{
Soheila Refahi, ${ }_{1}$ Bagher Minaei, ${ }^{2}$ Gholam Hassan Haddadi, ${ }^{3}$ Samideh Khoei, ${ }^{4}$ Azam Bakhtiarian, ${ }^{5}$ \\ Masoud Pourissa, ${ }^{6}$ and Abbas Takavar ${ }^{7, *}$ \\ ${ }^{1}$ Department of Medical Physics, Ardabil University of Medical Sciences, Ardabil, Iran \\ ${ }^{2}$ Department of Anatomy, Faculty of Medicine, Tehran University of Medical Sciences, Tehran, Iran \\ ${ }^{3}$ Department of Radiology, Paramedical School, Shiraz University of Medical Sciences, Shiraz, Iran \\ ${ }^{4}$ Department of Medical Physics, Iran University of Medical Sciences, Tehran, Iran \\ ${ }^{5}$ Department of Pharmacology, Faculty of Medicine, Tehran University of Medical Sciences, Tehran, Iran \\ ${ }^{6}$ Neurosciences Research Center, Tabriz University of Medical Sciences, Tabriz, Iran \\ ${ }^{7}$ Department of Medical Physics, Faculty of Medicine, Tehran University of Medical Sciences, Tehran, Iran \\ "Corresponding author: Abbas Takavar, Department of Medical Physics, Faculty of Medicine, Tehran University of Medical Sciences, Tehran, Iran. Tel: +98-2166466383, Fax: \\ +98-2166482654, E-mail: takavar@sina.tums.ac.ir
}

Received 2014 June 14; Revised 2014 October 15; Accepted 2014 October 19.

\begin{abstract}
Background: Radiotherapy of the thorax often causes lung inflammation leading to fibrosis.

Objectives: The aim of this study was to investigate whether the use of glycyrrhizic acid (GLA) could improve the development of lung fibrosis in irradiated animals.

Materials and Methods: Wistar rats were divided into four groups. Group A rats received thoracic irradiation. Rats in group B received GLA and irradiation. Group C received GLA and no irradiation. Group D received no GLA and irradiation. GLA was administered at a dose of $4 \mathrm{mg} / \mathrm{kg}$ body weight using an intraperitoneal injection one hour before thoracic irradiation. Radiation therapy was delivered on a Cobalt-60 unit using a single fraction of $16 \mathrm{~Gy}$. The animals were sacrificed at 32 weeks following thoracic irradiation. The lungs were dissected and blind histopathological evaluation was performed.

Results: Histopathologically, a decrease (statistically not significant) in the thickening of alveolar or bronchial wall, formation of fibrous bands, and superimposed collagen were noted in the animals in group B as compared to the animals in group A.

Conclusion: In this experimental study, administration of GLA one hour before thoracic irradiation may be a protective agent against radiation-induced fibrosis in animals and this model could be used in future studies.

Keywords: Lung fibrosis, Radioprotector, Glycyrrhizic Acid, Histopathology
\end{abstract}

\section{Background}

The lung as a radiosensitive organ of the body imports a problem for radiotherapy of the thorax (1). The lung's reaction to radiation in animal models and human are similar and can be divided into acute and chronic phases. It is reported that these reactions are not necessarily related; therefore, the chronic phase can appear without being preceded by the acute phase. Radiation induced-acute pneumonitis and chronic fibrosis develop within 6 months and 6 - 12 months, respectively to radiation doses $\geq 8$ Gy. Acute phase involves edema of the alveolar spaces, with increasing infiltration of mononuclear and inflammatory cells in the alveolar spaces. The chronic phase involves repair proliferation of alveolar cells that leads to changes in connective and vascular tissue (2). Radiation-induced lung damage is a common and critical difficulty that restricts the doses that can be released in radiation therapy (3). Stud- ies have shown that radiation-induced pulmonary fibrosis is caused by a fixed remodeling of fibrous tissue and long-time fibroblast activation (4-7). It seems that proinflammatory and profibrotic cytokines, oxidative stress, vascular injury, and coagulation cascade have an essential role in the progress of radiation fibrosis (8-10). Some studies suggest that radiation causes a high production of reactive oxygen species (ROS), which may be related to tissue hypoxia. ROS induces a cascade of cytokines and this has a central role in the non-healing wound response that perpetuates lung damages (11-14). Therefore, biological modifiers, such as antioxidants, have been studied to manipulate this process to minimize the progress of radiationinduced lung fibrosis. A massive matter in the evaluation of radioprotective agents potential benefit during radiation exposure is the development of radioprotectors (15). Root extracts of the plant Glycyrrhiza glabra L. known 
as Yashtimadhu, in Ayurveda have been used to cure different illnesses because of its anti-inflammatory, antibacterial, and immune-modulating properties (16). The active compounds of the extract have been reported to have an immune-modulating antioxidant. One famous component of the extract is glycyrrhizic acid (GLA), a triterpenoid saponin glycoside (Figure 1) (17-19). There are different antioxidant compounds in liquorice root and the literature supports that a wide range of pharmacological properties such as anticarcinogenic and anti-immune-mediated cytotoxicity is seen in the GLA (20).

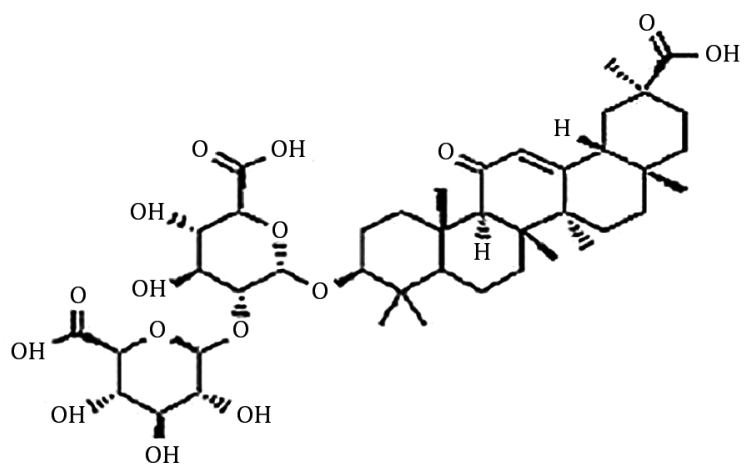

Figure 1. Schematic chemical structure of glycyrrhizic acid (GLA)

\section{Objectives}

In this study we tested the hypothesis that GLA can alter the progress of radiation- induced lung fibrosis by acting as an antioxidant by scavenging ROS.

\section{Materials and Methods}

\subsection{Animals}

Twenty male Wistar rats weighting about $190 \mathrm{~g}$ were used in this study. The animals were obtained from the vivarium section of the department of pharmacology, Tehran University of Medical Sciences. Five of these rats were housed together in metal wire netting cages, with the room temperature maintained at $20-22^{\circ} \mathrm{C}$, relative humidity of $50 \%-70 \%$, and an airflow rate of 15 exchange/hour, to 12 hours alternate light and dark cycle. Animals had free access to tap-water in glass bottles and standard rat chow. All the procedures in this study are in accordance with the guidelines for care and use of laboratory animals, adopted by the ethics committee of Tehran University of Medical Sciences (210/27686, Nov3, 2002).

\subsection{Radiation Schedule}

Prior to irradiation, the animals in groups A and B were anesthetized with an intraperitoneal (IP) injection of ketamine hydrochloride, $80 \mathrm{mg} / \mathrm{kg}$ body weight, and xylazine, $5 \mathrm{mg} / \mathrm{kg}$ body weight (Alfasan, Woerden-Holland). Positioning was facilitated using a Lucite fixation setup, making it possible to irradiate five animals simultaneously. The animals were in the supine position and the whole thoracic region was irradiated by a Cobalt-60 unit (Theratron 780, AE Canada Ltd., Canada) at a depth of $1 \mathrm{~cm}$, at a focuse-thoracic cage distance of $80 \mathrm{~cm}$, and single dose of $16 \mathrm{~Gy}$, with a dose rate of 99/84 cGy/min. Following radiation, the animals were closely observed until recovery from anesthesia.

\subsection{Experimental Protocol}

Animals were randomized into four experimental groups with five rats per group. The first group of animals (group A) had irradiation to the thoracic region. The second group of animals (group B) had thoracic irradiation plus GLA. The third group (group C) had GLA. The fourth group (group D) had no thoracic irradiation and GLA.

Group B and C received GLA ( $4 \mathrm{mg} / \mathrm{kg}$ body weight in double distilled water) via IP injection (21) one hour before irradiation.

\subsection{Histopathological Evaluation}

The animals underwent euthanasia at 32 weeks following irradiation. Prior to euthanasia, the animals received anesthesia using ketamine $50 \mathrm{mg} / \mathrm{kg}$ administered using an IP injection. Euthanasia was performed by transcardiac perfusion using $0.9 \%$ sodium chloride. The animals were sacrificed and their chests were opened immediately for access and examination of the lungs. The lungs were dissected, instilled with 10\% buffered formaldehyde, kept in $10 \%$ buffered formaldehyde for 24 hours, embedded in paraffin, sliced into $5 \mu \mathrm{m}$ thick sections, and stained using hematoxylin and eosin (H\& E). The histological examination was performed by a histologist, who was blinded to the experimental protocol, and viewed under the light microscope (LM), (BX50, Olympus Corporation, Tokyo, Japan) using a grid system. The term "fibrotic" as a morphological term was used to explain an increase of connective tissue fibers under the light microscope in response to some insult. The pathologist uses the characteristic staining properties of collagenous ingredients of the fibrous tissue (2). In this study, fibrosis was defined as the thickened alveolar walls with superimposed collagen. As a quantitative end point, the extent of radiation-induced fibrosis was scored on a scale of 0 (normal lung) to 3 (severe superimposed collagen) as described in Table 1(3). After assessment of all the 
sections for each animal, the minimum (min) and maximum (max) fibrosis score and median values of the groups were calculated.

Table 1. Criteria for Scaling of Lung Fibrosis

\begin{tabular}{lc}
\hline Scale of Fibrosis & Histological Features \\
\hline $\mathbf{0}$ & Normal lung \\
$\mathbf{1}$ & Mild thickening of alveolar or bronchial wall \\
$\mathbf{2}$ & Formation of fibrous bands \\
$\mathbf{3}$ & Severe superimposed collagen \\
\hline
\end{tabular}

\subsection{Statistical Analysis}

The results are represented as min, max and median. Statistical analyses were performed using the Kruskal Wallis test and the Mann-Whitney U test contained in the SPSS software package (version 11.0) for windows 98 (SPSS Inc., Chicago, Ill, USA). A probability value less than 0.05 was considered significant.

\section{Results}

At the end of the histological examination, it was seen that animals in groups A and B had pulmonary fibrosis (Figures 2-5). The descriptive data for each group is shown in Table 2.

Kruskal Wallis test showed a significant difference among the four groups $(\mathrm{P}<0.001)$. When group A was compared with group $\mathrm{D}$, the difference was statistically significant with the Mann- Whitney U test $(P<0.001)$.

When group A was compared with group $B$, the difference was statistically significant with the Mann-Whitney $U$ test $(\mathrm{P}=0.002)$. When group $\mathrm{B}$ was compared with group $\mathrm{D}$, the difference was statistically significant with the MannWhitney U test $(\mathrm{P}<0.001)$. When group A was compared with group $C$, the difference was statistically significant with the Mann-Whitney $\mathrm{U}$ test $(\mathrm{P}<0.001)$. When group $B$ was compared with group $C$, the difference was statistically significant with the Mann-Whitney U test $(\mathrm{P}<0.001)$. No significant differences were observed between groups $\mathrm{C}$ and $\mathrm{D}$ with the Mann-Whitney U test $(\mathrm{P}=0.785)$.

\section{Discussion}

Radiation therapy as a treatment modality is widely used in the management of cancer. Radiation inducedfibrosis is a serious part of the spectrum of radiation damage and at the present time, cure for this condition is limited (22). The radioprotective agents can elicit their action by various mechanisms. Numerous pharmacologic effects of GLA include anti-inflammatory, anti- tumor and antioxidant properties. The broad spectrum of pharmacological activity inherent in this extract is confirmed by results of traditional investigations, which include antiinflammatory, antiviral, and immunomodulant (23). Afnan et al. (2012) indicated that GLA as a natural and safe photoprotective agent might be useful against UVB irradiation (24). Ward et al. (1990) demonstrated that the cellular injury associated with radiation therapy is predominately brought about as the result of the unstable ROS that are in constant reaction with the cellular DNA content (25).

Another study conducted by Kumar et al. (1988) indicated that activation of the antioxidant defense system needs protection against the damaging effects of the unstable ROS (26). There has been a continued interest for the identification of a safe and effective protectant that bears the potential to function as the scavenger of the unstable ROS and down-regulates the cellular injury associated with radiation therapy (27).

In the present study, in the group of animals that were administrated GLA and thoracic irradiation, a reduction in fibrosis was achieved, the difference was statistically significant when compared with the group of animals that had only received thoracic irradiation (Figures 2 and 3 ). When animals of group B that received thoracic irradiation and GLA were compared with animals of group D that received no GLA and thoracic irradiation, the difference was statistically significant. This issue may result in administration of low dose GLA. Therefore, it seems that long- term administration of GLA and other concentrations of this extract may produce more protection against radiation-induced lung fibrosis. However, many in vivo and in vitro examinations and clinical trials on this topic are still necessary for validation.

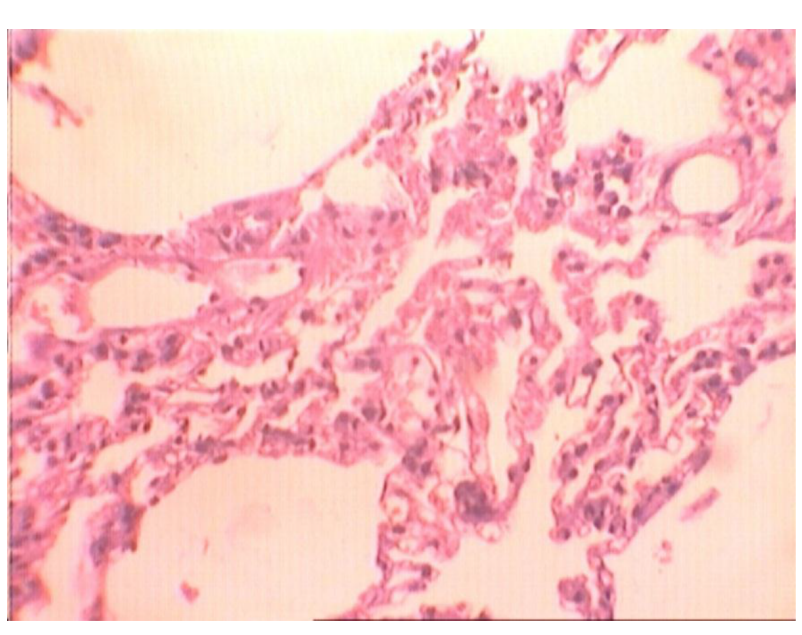

Figure 2. Histological lung tissue section of a rat from group A (H \& E $\times 400)$ 
Table 2. Descriptive Data in Four Groups ${ }^{\mathrm{a}}$

\begin{tabular}{|c|c|c|c|c|}
\hline Groups & Median & Minimum & Maximum & Mann-Whitney U Test P Value ${ }^{b}$ \\
\hline $\mathbf{A}$ & 3 & 2 & 3 & A vs $\mathrm{B}: \mathrm{P}=0.002 ; \mathrm{A}$ vs $\mathrm{C}: \mathrm{P}<0.001 ; \mathrm{A}$ vs $\mathrm{D}: \mathrm{P}<0.001$ \\
\hline B & 2 & 2 & 3 & B vs A: $P=0.002 ; B$ vs $C: P<0.001 ; B$ vs $D: P<0.001$ \\
\hline C & 0 & 0 & 1 & C vs $\mathrm{A}: \mathrm{P}<0.001 ; \mathrm{C}$ vs $\mathrm{B}: \mathrm{P}<0.001 ; \mathrm{C}$ vs $\mathrm{D}: \mathrm{P}=0.785$ \\
\hline D & 0 & 0 & 1 & D vs $A: P<0.001 ; D$ vs $B: P<0.001 ; D$ vs $C: P=0.785$ \\
\hline
\end{tabular}

${ }^{a}$ Groups: group A, thoracic irradiation only; group B, thoracic irradiation plus glycyrrhizic acid (GLA); group C, GLA only; Group D, no thoracic irradiation and GLA. ${ }^{\mathrm{b}}$ Difference was regarded significant if $\mathrm{P}<0.05$.

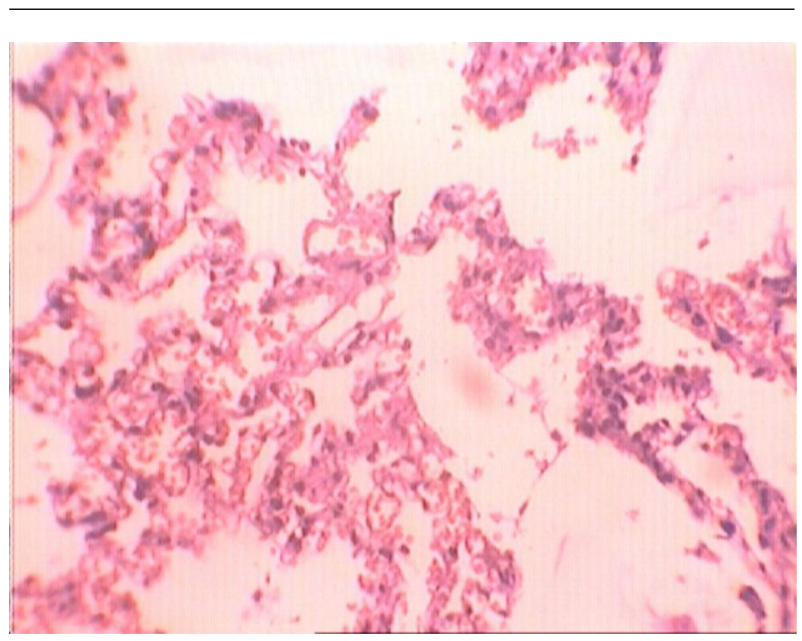

Figure 3. Histological lung tissue section of a rat from group B $(\mathrm{H} \& \mathrm{E} \times 400)$

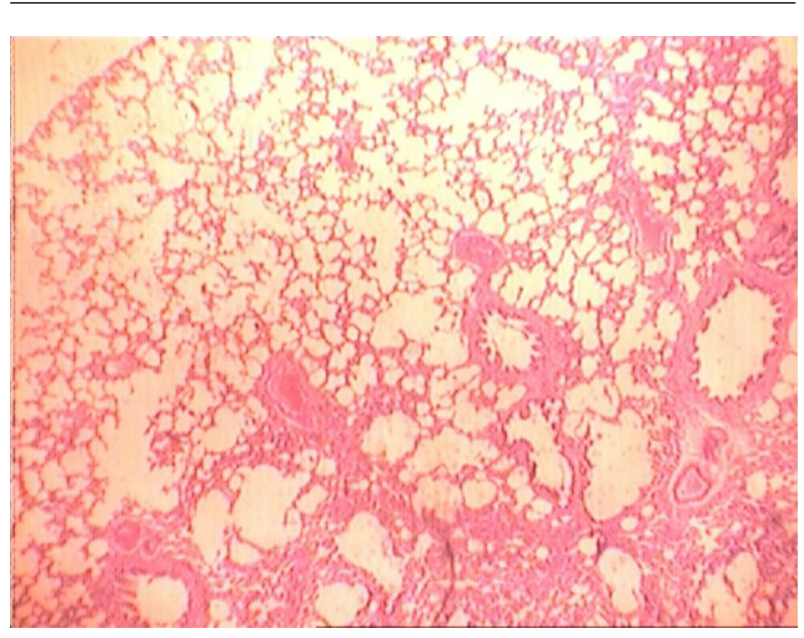

Figure 4. Histological lung tissue section of a rat from group $\mathrm{C}(\mathrm{H} \& \mathrm{E} \times 400)$

The results of the current study show that GLA may have a protective effect against radiation induced lung injury, as assessed by the severity of fibrosis using

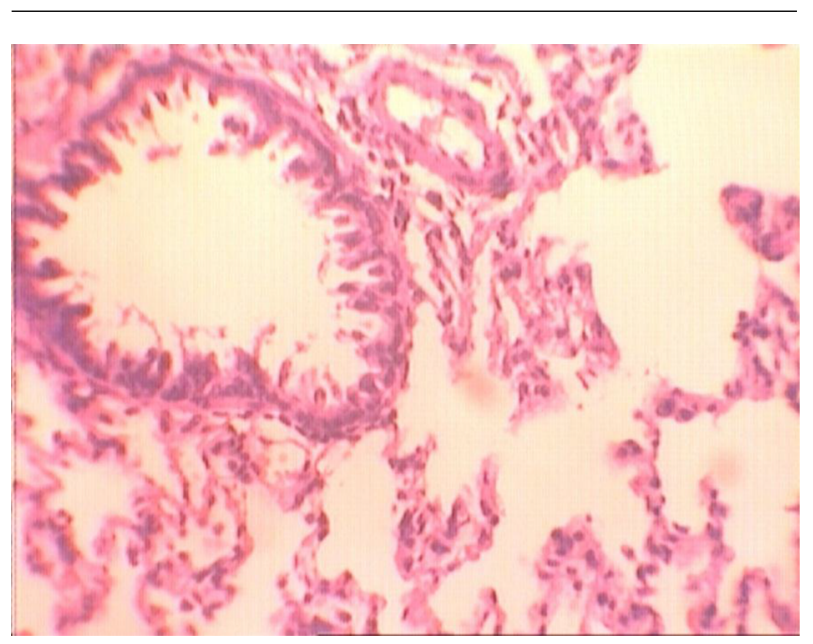

Figure 5. Histological lung tissue section of a rat from group D $(\mathrm{H} \& \mathrm{E} \times 400)$

histopathology. We could not find reports of the effectiveness of GLA as a protectant against lung injury induced by radiation therapy to compare with our results. But there are reports about radioprotective effects of GLA on different cells in vitro and ex vivo. Shetty et al. (2002) found that the root extract of Glycyrrhizia glabra L. protects microsomal membranes, as evident from reduction in lipid peroxidation, and it also protects DNA from radiation-induced strand breaks (28). Gandhi et al. (2004) implicated that an IP administration of GLA one hour before exposure to gamma radiation protected cellular DNA from radiation-induced strand breaks in peripheral blood leukocytes and bone marrow cells. Also, they demonstrated that pulse radiolysis studies indicated that GLA offered radioprotection by scavenging free radicals (21). Rossi et al. (2005) showed that use of GLA might lead to protection from the damage induced in humans by UVB radiation (20). Today there is a lot of interesting data on the prevention of radiation-induced lung injury, but none of it has so far been shown to be effective in a clinical setting. Previous studies showed effectiveness of radiopro- 
tectors such as WR-2721, vitamin E, captopril, melatonin, and genistein on radiation-induced lung injury (1, 3, 29-31). It seems that the combination of GLA with some radioprotectors may be useful in the mitigation effect of radiation on lung tissue. The incidence of radiation-induced injuries might reduce GLA administration to patients undergoing medical radiation. These findings suggest that the radioprotective effect of GLA on lung tissue should be studied in detail before translating the results of the present experimental study into clinical trials in order to alter the therapeutic index of radiation treatment. A single dose of GLA could be a limitation of this study. It is recommended that further studies with different doses of GLA should be performed to examine the radioprotective effect of GLA in the lung tissue in more detail.

In conclusion, according to this experimental study, administration of GLA one hour before thoracic irradiation may be a protective agent against radiation-induced fibrosis in animals and this model could be used in future studies.

\section{Acknowledgments}

We thank the Cancer Institute of Tehran University of Medical Sciences for their excellent assistance with the irradiation of the animals.

\section{Footnotes}

Authors' Contributions: Abbas Takavar and Soheila Refahi contributed to all parts of the study especially sampling, sacrificing, radiotherapy, data analysis and writing the manuscript. Bagher Minaei and Samideh Khoei conducted histopathology examination. Masoud Pourissa and Azam Bakhtiarian contributed to writing the manuscript. Gholam Hassan Haddadi developed the original idea and the protocol.

Financial Disclosure: There are no financial disclosures or conflicts of interest in this study.

Funding/Support: The work of authors is supported by grant No. 17951 from the vice chancellor of research at Tehran University of Medical Sciences, Tehran, Iran.

\section{References}

1. Calveley VL, Jelveh S, Langan A, Mahmood J, Yeung IW, Van Dyk J, et al. Genistein can mitigate the effect of radiation on rat lung tissue. Radiat Res. 2010;173(5):602-11. doi: 10.1667/RR1896.1. [PubMed: 20426659].

2. Coggle JE, Lambert BE, Moores SR. Radiation effects in the lung. Environ Health Perspect. 1986;70:261-91. [PubMed:3549278].
3. Bese NS, Munzuroglu F, Uslu B, Arbak S, Yesiladali G, Sut N, et al. Vitamin E protects against the development of radiation-induced pulmonary fibrosis in rats. Clin Oncol (R Coll Radiol). 2007;19(4):260-4. doi: 10.1016/j.clon.2006.12.007. [PubMed:17433970].

4. Stone HB, Coleman CN, Anscher MS, McBride WH. Effects of radiation on normal tissue: consequences and mechanisms. Lancet Oncol. 2003;4(9):529-36. [PubMed: 12965273].

5. Finkelstein JN, Johnston CJ, Baggs R, Rubin P. Early alterations in extracellular matrix and transforming growth factor beta gene expression in mouse lung indicative of late radiation fibrosis. Int J Radiat Oncol Biol Phys. 1994;28(3):621-31. [PubMed: 8113105].

6. Rodemann HP, Bamberg M. Cellular basis of radiation-induced fibrosis. Radiother Oncol. 1995;35(2):83-90. [PubMed: 7569029].

7. Rubin P, Johnston CJ, Williams JP, McDonald S, Finkelstein JN. A perpetual cascade of cytokines postirradiation leads to pulmonary fibrosis. Int J Radiat Oncol Biol Phys. 1995;33(1):99-109. doi: 10.1016/03603016(95)00095-G. [PubMed: 7642437].

8. Anscher MS, Kong FM, Andrews K, Clough R, Marks LB, Bentel G, et al. Plasma transforming growth factor beta1 as a predictor of radiation pneumonitis. Int J Radiat Oncol Biol Phys. 1998;41(5):1029-35. [PubMed: 9719112].

9. Fu XL, Huang H, Bentel G, Clough R, Jirtle RL, Kong FM, et al. Predicting the risk of symptomatic radiation-induced lung injury using both the physical and biologic parameters $\mathrm{V}(30)$ and transforming growth factor beta. Int J Radiat Oncol Biol Phys. 2001;50(4):899-908. [PubMed: 11429217].

10. Chen Y, Williams J, Ding I, Hernady E, Liu W, Smudzin T, et al. Radiation pneumonitis and early circulatory cytokine markers. Semin Radiat Oncol. 2002;12(1 Suppl 1):26-33. [PubMed: 11917281].

11. Poli G, Parola M. Oxidative damage and fibrogenesis. Free Radic Biol Med. 1997;22(1-2):287-305. [PubMed: 8958154].

12. Haroon ZA, Raleigh JA, Greenberg CS, Dewhirst MW. Early wound healing exhibits cytokine surge without evidence of hypoxia. Ann Surg. 2000;231(1):137-47. [PubMed:10636114].

13. Vujaskovic Z, Anscher MS, Feng QF, Rabbani ZN, Amin K, Samulski TS, et al. Radiation-induced hypoxia may perpetuate late normal tissue injury. Int J Radiat Oncol Biol Phys. 2001;50(4):851-5. [PubMed: 11429211].

14. Kang SK, Rabbani ZN, Folz RJ, Golson ML, Huang H, Yu D, et al. Overexpression of extracellular superoxide dismutase protects mice from radiation-induced lung injury. Int $J$ Radiat Oncol Biol Phys. 2003;57(4):1056-66. [PubMed: 14575837].

15. Arora R, Gupta D, Chawla R, Sagar R, Sharma A, Kumar R, et al. Radioprotection by plant products: present status and future prospects. Phytother Res. 2005;19(1):1-22. doi: 10.1002/ptr.1605. [PubMed: 15799007].

16. Agarwal SS, Singh VK. Medicinal Plants and Synthetic Peptides Part II: Synthetic Peptides. P Indian Natl Sci Acad. 1999;65:179-204.

17. Kroes BH, Beukelman CJ, van den Berg AJ, Wolbink GJ, van Dijk H, Labadie RP. Inhibition of human complement by beta-glycyrrhetinic acid. Immunology. 1997;90(1):115-20. [PubMed: 9038721].

18. Belinky PA, Aviram M, Mahmood S, Vaya J. Structural aspects of the inhibitory effect of glabridin on LDL oxidation. Free Radic Biol Med. 1998;24(9):1419-29. [PubMed: 9641259].

19. Vaya J, Belinky PA, Aviram M. Antioxidant constituents from licorice roots: isolation, structure elucidation and antioxidative capacity toward LDL oxidation. Free Radic Biol Med. 1997;23(2):302-13. [PubMed: 9199893].

20. Rossi T, Benassi L, Magnoni C, Ruberto AI, Coppi A, Baggio G. Effects of glycyrrhizin on UVB-irradiated melanoma cells. In Vivo. 2005;19(1):319-22. [PubMed: 15796192].

21. Gandhi NM, Maurya DK, Salvi V, Kapoor S, Mukherjee T, Nair CK. Radioprotection of DNA by glycyrrhizic acid through scavenging free radicals. J Radiat Res. 2004;45(3):461-8. [PubMed: 15613793].

22. Takavar A, Minaei B, Hadadi GH, Khoei S, Refahi S, Behrouzkia Z, et al Late histopathological findings in the thoracic irradiation: A preliminary study in the animal model. Life Sci J. 2013;10(7s). 
23. Pavlova SI, Uteshev BS, Sergeev AV. Possible Mechanisms of Antitoxicant, Anticarcinogen, and Antitumor Properties (A Review). Pharm Chem J. 2003;37(6):314-7. doi:10.1023/a:1026005931751.

24. Afnan Q, Adil MD, Nissar-Ul A, Rafiq AR, Amir HF, Kaiser P, et al. Glycyrrhizic acid (GA), a triterpenoid saponin glycoside alleviates ultraviolet-B irradiation-induced photoaging in human dermal fibroblasts. Phytomedicine. 2012;19(7):658-64. doi: 10.1016/j.phymed.2012.03.007. [PubMed: 22516896].

25. Ward JF. The yield of DNA double-strand breaks produced intracellularly by ionizing radiation: a review. Int J Radiat Biol. 1990;57(6):114150. [PubMed: 1971840].

26. Kumar KS, Vaishnav YN, Weiss JF. Radioprotection by antioxidant enzymes and enzyme mimetics. Pharmacol Ther. 1988;39(1-3):301-9. [PubMed: 3059373].

27. Weiss JF, Landauer MR. Radioprotection by antioxidants. Ann NYAcad
Sci. 2000;899:44-60. [PubMed: 10863528].

28. Shetty TK, Satav JG, Nair CK. Protection of DNA and microsomal membranes in vitro by Glycyrrhiza glabra L. against gamma irradiation. Phytother Res. 2002;16(6):576-8. doi: 10.1002/ptr.927. [PubMed: 12237818].

29. Merrill WW. Radiation-induced lung injury 2011. Available from: www.uptodate.com.

30. Serin M, Gulbas H, Gurses I, Erkal HS, Yucel N. The histopathological evaluation of the effectiveness of melatonin as a protectant against acute lung injury induced by radiation therapy in a rat model. Int $J$ Radiat Biol. 2007;83(3):187-93. [PubMed: 17378527].

31. Maasilta P. Radiation-induced lung injury. From the chest physician's point of view. Lung Cancer. 1991;7(6):367-84. doi: 10.1016/01695002(91)90388-m. 